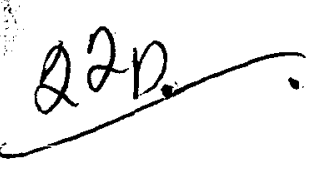

NASA TECHNICAL
MEMORANDUM
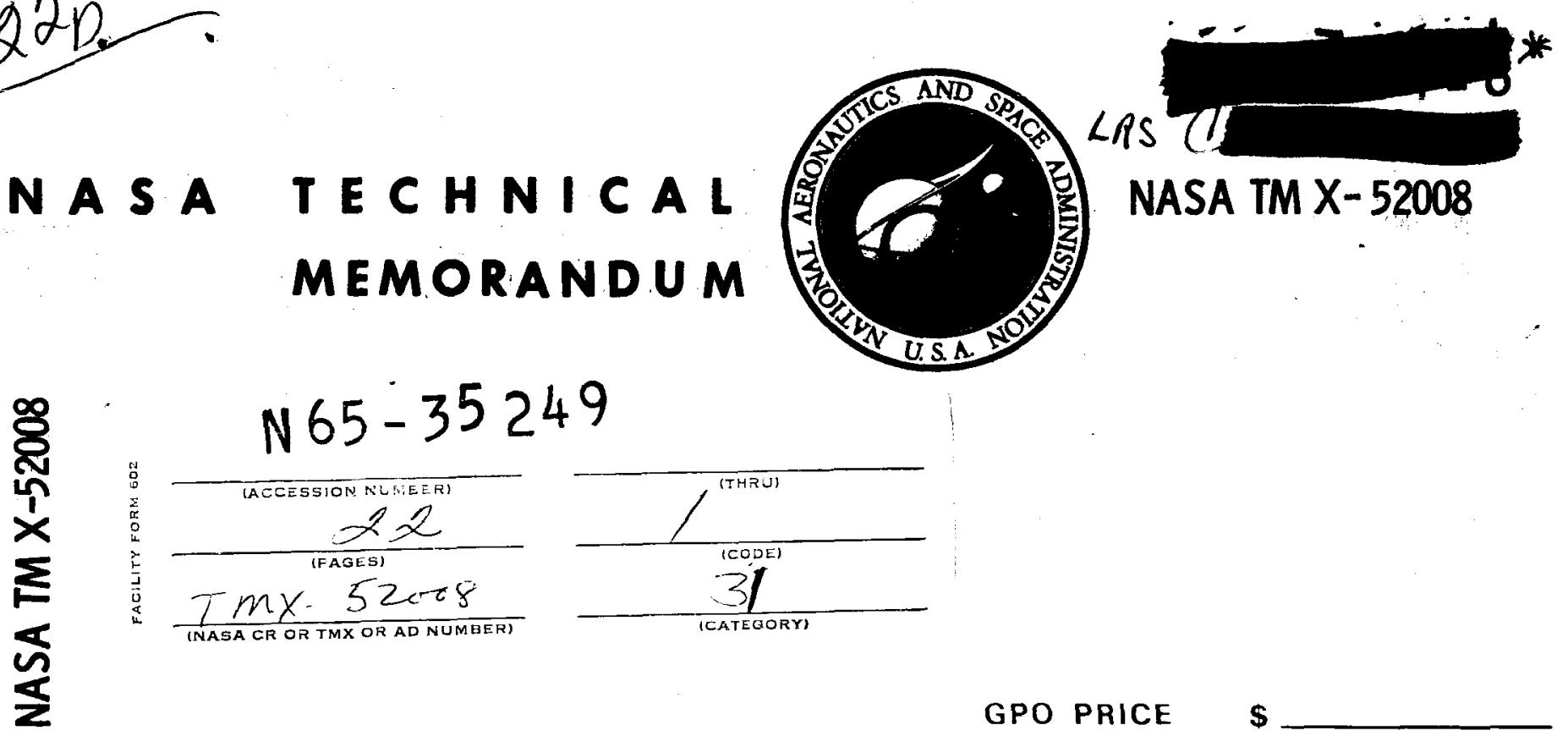

GPO PRICE \$

CFSTI PRICE(S) \$

Hard copy $(\mathrm{HC})$

Microfiche (MF)

3 July 65

\title{
A SPACECRAFT FOR ION THRUSTOR FLIGHT TESTS
}

by Harold Gold

Lewis Research Center

Cleveland, Ohio

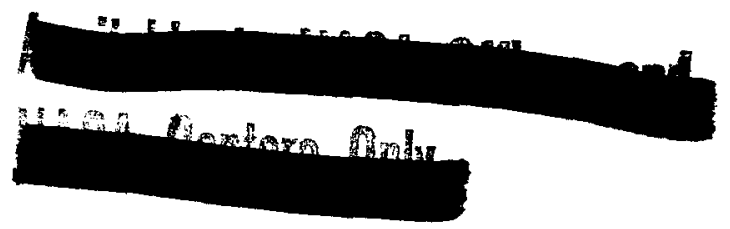

TECHNICAL PREPRINT prepared for National

- Aeronautics Meeting and Production Forum sponsored by the Society of Automotive Engineers and the American Society of Mechanical Engineers

New York, New York, April 27-30, 1964 


$$
1-27-03
$$

\author{
TECHNICAL MEMORANDUM
}

$$
\begin{gathered}
\text { TA SPACECRAFT FOR ION THRUSTOR FLIGHT TESTS J } \\
\text { P.A. } \\
C A-N A S A, \begin{array}{c}
\text { Lewis Research Center, } \\
\text { Cleveland, Ohio } \\
1609742
\end{array}
\end{gathered}
$$

1

*

TECHAAI PREPRINT prepared for

Natlot Aeronating and Production Forum, sponsored by so s $A E$ and

Now Yox, (Aprit 27-30) 1964

(NASA TMX-52008)

Unc.

NATIONAL AERONAUTICS AND SPACE ADMINISTRATION 


\section{A SPACECRAFT FOR ION THRUSTOR FLIGHT TESTS}

by Harold Gold

Lewis Research Center

National Aeronautics and Space Administration

Cleveland, Ohio

\section{ABSTRACT}

35249 A

A spacecraft that will be used for flight tests of ion thrustors is described. The spacecraft has been designed to provide measurements of thrustor electrical parameters and thrust. The tests to be carried out will determine the validity of ion thrustor performance data that has been obtained in vacuum chambers. The spacecraft, which will carry two thrustors of different construction, will be launched into a ballistic trajectory by the INASA Scout vehicle. The test time will be approximately 1 hour.

\section{INTRODUCTION}

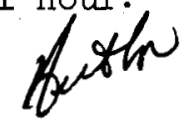

Ion thrustor developers have been waiting for tests of ion propulsion systems in space for several years. Data that have thus far been obtained in vacuum chambers, in the course of ion thrustor development, may not be completely valid because of the uncertain influence of the chamber walls. A review of current ion propulsion technology and an extensive bibliography is presented in reference 1 .

The SERT-I spacecraft, which is now in the final stage of development, will provide measurements of thrustor electrical parameters and thrust during a l-hour ballistic flight. The development of the SERT-I spacecraft was begun in the summer of 1961 under the direction of the Marshall Space Flight Center of NASA. Project direction was transferred at the end of 1961 to the Lewis Research Center of NASA. 
This paper presents a description of the SERT-I spacecraft and of the ion thrustor systems as they have been developed through the extensive component and systems tests of the past 2 years.

\section{BASIC DESIGN PHILOSOPHY}

The attractiveness of the ion thrustor for space propulsion lies in its capability to produce values of specific impulse that are more than a decade higher than that produced by chemical rocket systems. Because of the power required by an accelerator is proportional to the product of specific impulse and thrust, however, the maximum electric power aboard the spacecraft determines the thrust if high values of specific impulse are to be achieved. By way of illustration, a 1-pound electric thrustor operating at a specific impulse of 5000 seconds would require, at 100 percent conversion efficiency, electric power in excess of 100 kilowatts. With the electric energy that it is currently feasible to store aboard a spacecraft of a few hundred pounds, the ion accelerator can operate for significant time periods at a specific impulse of 5000 seconds or greater with only millipounds of thrust. Therefore, in the design of the SERT-I spacecraft, consideration had to be given to the flight time, the power supply weight, and the feasibility of detecting and measuring thrust.

In the planning stage of the SERT-I spacecraft, the mission time was 1 hour and the nominal ion thrustor specifications were: thrust, 0.01 pound, specific impulse, 5000 seconds, thrustor power efficiency, 50 percent. The required input power that corresponds to the se specifications is 2180 watts. Silver-zinc batteries have a capacity of approximately 30 watt-hours per pound. On this basis, the battery weight for the 1-hour 
•

mission is 73 pounds. This battery weight is compatible with a total spacecraft weight of 350 pounds, which the assigned launch vehicle - the NASA Scout, can loft into a ballistic trajectory that yields approximately 1 hour at altitudes above 250 nautical miles.

A thrust of 0.01 pound will produce a linear acceleration of $2.9 \times 10^{-5} \mathrm{~g}$ on a 350 -pound spacecraft. Because of the difficulties associated with the measurement of so small a linear acceleration, it was decided to apply the thrust so that the angular momentum, rather than the linear momentum, of the spacecraft would be varied. Accordingly, a spinstabilized spacecraft, with the ion thrustor mounted to apply torque about the spin axis, was selected. With this arrangement, thrust can be measured through detection of the rate of change of spacecraft spin rate. A very significant feature of this technique is the time integration of thrust by the spinning spacecraft.

The 1-hour flight time is to be shared by two ion thrustors. The use of two thrustors on the spacecraft provides an important redundancy and provides an opportunity for evaluation of two thrustor designs. In order to provide the maximum torque-inertia ratio and to remain within the constraints of the payload heat shield, the thrustors are mounted on pivoted brackets that swing outward after trajectory insertion. The general configurations of the payload during launch and in free flight are shown in figures 1 and 2 , respectively. For stable rotation of the spacecraft about the spin axis, it is necessary that the spin axis moment of inertia be dominant. This requirement dictated the characteristic top-like shape of the spacecraft. A photograph of a prototype spacecraft in a Lewis Research Center vacuum chamber is shown in figure 3. 


\section{ION THRUSTOR DESIGN}

Principle of Operation

The ion thrustor produces thrust by the acceleration of charged particles in an electric field. For a net thrust to be obtained, it is necessary that the charged-particle exhaust be neutralized. According to reference 1, this neutralization requires (1) equal rates for the ejection of opposite charges (current neutralization) to avoid accumulation of charge on the space vehicle and (2) equal densities of opposite charges in the beam (charge neutralization) to avoid space charge effects in the beam. The essential components of an ion thrustor are the subsystems for

(1) propellant feed, (2) ionization, (3) accelerating electrode, and (4) beam neutralization.

\section{Basic Thrustor Characteristics}

The principal thrustor characteristics and operating parameters of the two SERT-I thrustors are shown in table I. The beam diameters of 3 and 4 inches, as shown in the table, result in thrustors of considerable bulk. Because gas pressures and electrical forces are low, the thrustors can be constructed essentially of thin-walled tubes and plates, yielding lightweight assemblies. Thick walls need be used only where structural rigidity is required for dimensional stability, as in the case of electrode alinement and spacing. Thin-walled structures are inherently prone to multiple vibration modes. For this reason, the development of these structures to withstand the severe vibration of the Scout vehicle has taken considerable effort. Because many of the structural components must be electrically insulated for several kilovolts potential, rigid clamping 
is not often possible in the structures, and many of the usual reinforcing and damping techniques cannot be applied.

The choice of propellant for each thrustor is based on suitability to the ionization process. The specific impulses are 5000 seconds for the electron-bombardment thrustor and 8250 seconds for the contact-ionization thrustor. The power efficiency is approximately 50 percent for both thrustors, and the power losses are due principally to thermal radiation from the ionizing and neutralizing systems.

\section{Contact-Ionization Thrustor}

A schematic diagram of the contact-ionization thrustor is shown in figure 4. Cesium vapor flows from an electrically heated boiler and through an electrically heated porous tungsten ionizer. The porous tungsten also serves as the propellant flow-control restriction. Propellant feed control is accomplished through regulation of the boiler temperature. A solenoid valve, which is between the boiler and the ionizer, is employed for rapid turnon or turnoff of propellant flow. The electrode array is made up of focus, accelerator, and decelerator electrodes. The focus electrode is held at a positive potential of 4500 volts above spacecraft potential in common with the ionizer. The accelerator electrode is held at 2000 volts below spacecraft potential, and the decelerator electrode remains at spacecraft potential. The potential difference between the decelerator electrode and the ionizer controls the final jet velocity, while the potential difference between the accelerator electrode and the ionizer determines the saturation mass flow rate. The boiler temperature is regulated to maintain the propellant feed rate slightly below the 
saturation rate. The beam is neutralized by electrons that are emitted from a tantalum filament that is downstream of the decelerator electrode. As indicated in figure 4, electric power must be supplied to the thrustor in several forms and potentials.

The thrustor utilizes an annular construction. The tungsten ionizer, the electrode passages, and the neutralizer filament are annuli that are parallel and concentric. The electrode passages and the discharge face of the ionizer annulus are approximately $3 \frac{1}{4}$ inches outside diameter and $\frac{1}{4}$ inch wide. Support and spacing insulators are arranged to provide completely unobstructed annuli. The neutralizer filament is a fine wire that is held approximately $1 / 4$ inch downstream of the decelerator electrode along the outer periphery of the annulus.

The thrustor assembly is mounted to the spacecraft in a cylindrical magnesium pod. The pod is evacuated to prevent adsorption of oxygen gas by the tungsten ionizer during launch operations. The pod is opened in space by ejection of a cylinder cap at the electrode end. A photograph of the thrustor, taken during operation in a vacuum chamber and showing the open pod configuration, is presented in figure 5.

Because the contact-ionization thrustor is enclosed in a evacuated pod, it is programmed to operate during the first half of the flight period. The electron-bombardment thrustor, which is not enclosed in a pod, will be permitted to outgas during the period of operation of the contact-ionization thrustor. 


\section{Electron-Bombardment Thrustor}

A photograph of a cutaway model of the electron-bombardment thrustor is shown in figure 6, and an electrical schematic diagram is shown in figure 7. Mercury vapor flows from an electrically heated boiler into the ionization chamber. The rate of propellant feed is controlled by a porous stainless-steel plug through regulation of the boiler temperature. A circular baffle plate is located just downstream of the plug to induce uniform distribution of the mercury vapor. The bombarding electrons are emitted from a tantalum filament cathode and are attracted to a cylindrical shell anode that is 50 volts positive with respect to the cathode. The anode shell and the cylindrical ionization chamber wall are coaxial with the thrust axis. A coaxial magnetic field is generated by a coil that is wound around the ionization chamber. The magnetic field causes electrons to move from the cathode to the anode in acomplexpath and thereby increases the probability of collision with mercury atoms. A perforatedscreen electrode covers the downstream end of the ionization chamber. The accelerator electrode has matched perforations and is spaced approximately 1/16 inch downstream of the screen electrode. The ionization chamber and the screen electrode are maintained at a potential of 2500 volts above the spacecraft potential, and the accelerator electrode is maintained at 2000 volts below the spacecraft potential. The tantalum neutralizer filament (not shown in fig. 7) is grounded to the spacecraft. As in the case of the contact-ionization thrustor, the boiler temperature is regulated to maintain the propellant feed rate slightly below the accelerator electrode saturation flow rate. 
Figure 8 is a photograph of a flight thrustor. The external screening is grounded to the spacecraft. It functions to block the flow of electrons from the neutralizer filament to the walls of the ionization chamber.

\section{Power Supplies}

As pointed out earlier, silver-zinc batteries can provide the required electrical power for the 1-hour flight duration; however, such batteries cannot be readily packaged to provide the high voltages and circuit action required by the thrustors. For this reason, converters were.developed to change the relatively low battery voltages to the kilovolt range and to provide the control functions that are required by the thrustors.

Solid-state converters were selected on the basis of minimum weight and adaptability to the control requirements. For complete redundancy, separate converters are coupled to the two thrustors. The two converters, which are similar in method of operation, use transistor choppers, transformer voltage conversion, and solid-state rectifiers. Voltage and current regulation are obtained through variation of the conducting time period (pulse-width modulation) of the transistor choppers. A battery voltage of 56 volts was selected on the basis of compatibility with battery packaging and with voltage and current limits of available transistors for the chopper circuits. The battery is directly connected to the chopper transistors of both converters. Converter turnon and turnoff is controlled by switching power to the pulse-width-modulation oscillator in each converter. The currents drawn by these oscillators are small fractions of the total 
converter input currents and can be switched by relatively low current relays. Chopper transistor leakage during prelaunch and flight nonoperating periods is negligible.

A principal feature of the converters is the protection provided against damage through output short circuits that are generated by electric arcs. Because of the high voltage employed and the presence of a low density plasma, the ion thrustor presents an electrical load that is very susceptible to arcing. In the converters, the circuits that float on the high positive voltage are susceptible to damage during arcing from this voltage through stray circuit capacitance to spacecraft ground. The chopper transistors are subject to momentary but damaging periods of overvoltage during output arcing through interwinding capacity in the transformers. Because of these effects, the converters incorporate electrostatic shielding in transformers, breakdown-diode overvoltage protection for chopper transistors, and output current-limiting through feedback and through fixed resistors between the converter and thrustor. The thrustor electrodes exhibit very high inpedances during thrustor operations, and, therefore, high values of converter output resistance can be employed at no detriment to thrustor performance. However, the voltage drop and power dissipation prevent the use of high series resistance values. Nevertheless, series resistance of a few hundred ohms has been found to be very effective in improving converter reliability. 
Because of the possibility of outgassing during the flight, precautions have been taken against arcing and corona discharge within the converters. For this purpose, the converter for the electron-bombardment thrustor is housed in pressure-tight containers. The converter for the contact-ionization thrustor is housed in unsealed containers but utilizes sealed high-voltage modules; all high-voltage terminals are coated with insulation. Both approaches have worked well in vacuum chamber tests, but extreme care has been found to be necessary in sealing and potting.

\section{INSTRUMENTATION AND TELEMETRY}

\section{Instrumentation Problems}

Instrumentation of the thrustors and power converter for transmission of operating parameters through the telemetry system is complicated by the high voltage levels that are employed. All parameter signals are either initially generated or later modified to the conventional telemeter input voltage range of 0 to 5 volts. Converter parameters are measured on the a-c side only. This permits transformer reduction of the high voltage levels. For transmission of parameters, such as the magnetic field current in the electron-bombardment thrustor, which is a direct current of approximately 15 amperes flowing in a low-resistance circuit that is grounded at 2500 volts above the telemetry system ground, special transducers have been developed. Spacecraft performance monitoring follows conventional telemetry practice.

Special instrumentation that is carried for diagnosis of thrustor performance consists of a beam power probe that will sweep across the discharge beam of the electron-bombardment thrustor and an electric field 
meter that will give a qualitative indication of beam neutralization. The instrumentation that is used for thrust measurement is described in a later section.

\section{Telemetry System}

Aside from the special requirements of the thrust detection system the on-board and ground station requirements of the SERT-I flight can be met by conventional FM/FM equipment. For the purposes of the experiment, thrustor observations do not require measurements of rapidly fluctuating variables. For this reason, all thrustor data, other than thrust, will be sampled rather than continuously measured. Sampling is obtained by means of two 45 segment 2-cycle-per-second commutators. The output of each commutator is fed into a subcarrier oscillator for transmission. Each of the two commutator links is connected to separate transmitters. Critical data will be carried on both commutator links. In addition to the commutator subcarriers, a subcarrier in each of the transmission links is utilized by the thrust detection system and a third subcarrier in each transmission link will carry the program information.

\section{Command System}

In addition to the usual function of providing in-flight control of the spacecraft, the SERT-I command system will demonstrate the feasibility of (or difficulty in) the transmission of radio commands to a spacecraft that is propelled by an ion thrustor. It is considered possible that RF generated by arc or plasma oscillations can either saturate the command receiver, or equally serious, cause false command. Special attention was 
given to these possibilities in the design and development of the command system.

A command is generated by the transmission of two audio tone bursts, 1 second apart. Five tones are used to obtain 10 relay closures. A command will be put into effect with an amplitude of 0.25 volt at the receiver output with the receiver saturated with random noise. Under the condition of noise saturation, the theoretical probability of the occurrence of a false command is less than 10-8. A transmitted power of approximately 2 kilowatts will be employed, and the transmitter will radiate through a large parabolic antenna that will track the spacecraft.

Thrust Detection System

The thrust detection system will continuously monitor the angular momentum of the spacecraft. Thrust will be inferred from changes in angular momentum. Because of the thrust-integrating action of the spinning spacecraft, very low instrumentation accuracy will be sufficient for thrust, detection, if thrust is continuously produced for the $1 / 2$-hour that is to be allotted to each thrustor. Nevertheless, the SERT-I spacecraft will carry instrumentation of the highest accuracy in order to assure thrust measurements in the event of deviations from expected thrustap performance or failure of thrustor or spacecraft after a short interval of thrust. The expected thrust of the contact-ionization thrustor will cause the spacecraft spin rate to change at approximately 0.14 percent per minute and that of the electron-bombardment thrustor approximately 0.67 percent minute. Thus, for 30-minute thrusting intervals, the spin rate can change 4.2 and 20 percent. 
The thrust detection system comprises three independent subsystems. Two of the subsystems are solar cell spin period detectors. The third subsystem utilizes an accelerometer that is mounted so that its sensitive axis is perpendicular to and intersects the spacecraft spin axis.

Each solar cell subsystem employs a silicon photocell that is housed behind a narrow slit. The cells are mounted on the periphery of the spacecraft with the slit parallel to the spin axis. The two cells are spaced $180^{\circ}$ apart. The slit and cell combination and associated circuitry will generate one pulse each revolution. Each solar cell subsystem utilizes a separate telemetry link. The received pulses will be fed into clockcontrolled electronic counters for period measurement. For pure spin, the system error in spin period measurement is expected to be less than 0.1 percent in the observation of a single revolution.

The output of an accelerometer that is mounted along one of the principle axes of a freely rotating body will contain information about motion about all three principal axes. Hence, the accelerometer subsystem will provide the necessary information concerning possible complex motion of the spacecraft. Measurement of spacecraft precession and nutation will be essential if motion about the transverse axes is large and if there is energy transfer from the transverse axes to the spin axes.

The on-board accelerometer system will provide a frequency modulated output in the low subcarrier frequency range that will directly modulate each telemetry transmitter. On the ground, a sharp cutoff band-pass filter will extract the accelerometer system signal frequency from the received telemeter signal frequencies. The output of the filter will be fed into 
electronic counters. The stability and sensitivity of the complete spacecraft and receiving station system is such that ion thrustor thrust of as little as a 10-second duration will be measurable, with an uncertainty of approximately 0.05 millipound.

\section{SPACECRAFT STRUCTURE}

As discussed earlier, the top-like shape of the SERT-I spacecraft was dictated by the thrust measurement method. The basic support structure consists of a flat, circular baseplate supported on a cylindrical pedestal (see fig. 1). The baseplate has a ribbed understructure and is machined from a fonged magnesium billet. The supporting pedestal is also machined from a magnesium billet. The pedestal is clamped to a conical adapter that mates the spacecraft to the Scout fourth stage. The adapter is of welded and riveted aluminum sheet. The adapter pedestal clamp is opened by firing explosive bolts to separate the spacecraft from the Scout fourth stage.

A welded aluminum box frame is mounted on the top center of the baseplate. In this structure and in the pedestal below it are mounted the basic spacecraft gear: the programmer, the power distributor, the telemetry signal conditioning and switching gear, and the command receiver. The heavy components, such as batteries and power converters, are mounted on both sides of the baseplate alongside the central frame and pedestal. This mass distribution provides a dominant roll axis moment of inertia. The thrustor mounting arms are hinged near the outer edge of the baseplate. The deployment linkage is locked to the central pedestal and is released by an explosively actuated latch to permit outward deployment of 
the thrustors. The deployment is centrifugally actuated with the rate being limited by hydraulic dampers.

Components that are mounted on top of the baseplate are tied structurally to the center frame and the power converter housings that are mounted to the lower side of the baseplate are tied to the center pedestal. These ties are employed to suppress vibration resonances.

\section{CONCLUDING REMARKS}

In spite of the uncertain influence of the walls in vacuum chamber operation of ion thrustors, it is considered very probable that the thrustors carried by SERT-I will produce thrust in space. If SERT-I data indicate that beam neutralization is completely effective, the development of ion thrustors for space missions can continue in vacuum chambers. However, if beam neutralization is of limited effectiveness, a new program of vacuum chamber and flight tests may be undertaken.

\section{REFERENCE}

1. Mickelsen, W. R., and Kaufman, H. R.: Status of Electrostatic Thrustors for Space Propulsion. NASA TNN D-2172, 1864. 
TABLE I - PRINCIPAL THRUSTOR CHARACTERISTICS AND OPERATING PARAMETERS

$\begin{array}{rr}\begin{array}{c}\text { Electron- } \\ \text { bombardment } \\ \text { thrustor }\end{array} & \begin{array}{r}\text { Contact- } \\ \text { ionization } \\ \text { thrustor }\end{array} \\ 3.9 & 3.2 \\ 7.5 & 4.0 \\ 9.3 & 14 \\ \text { Mercury } & \text { Cesium } \\ 5000 & 8250 \\ 1400 & 610 \\ 50 & 51 \\ 80 & 96 \\ 6.4 & 1.25 \\ 280 & 50\end{array}$


임
足
占
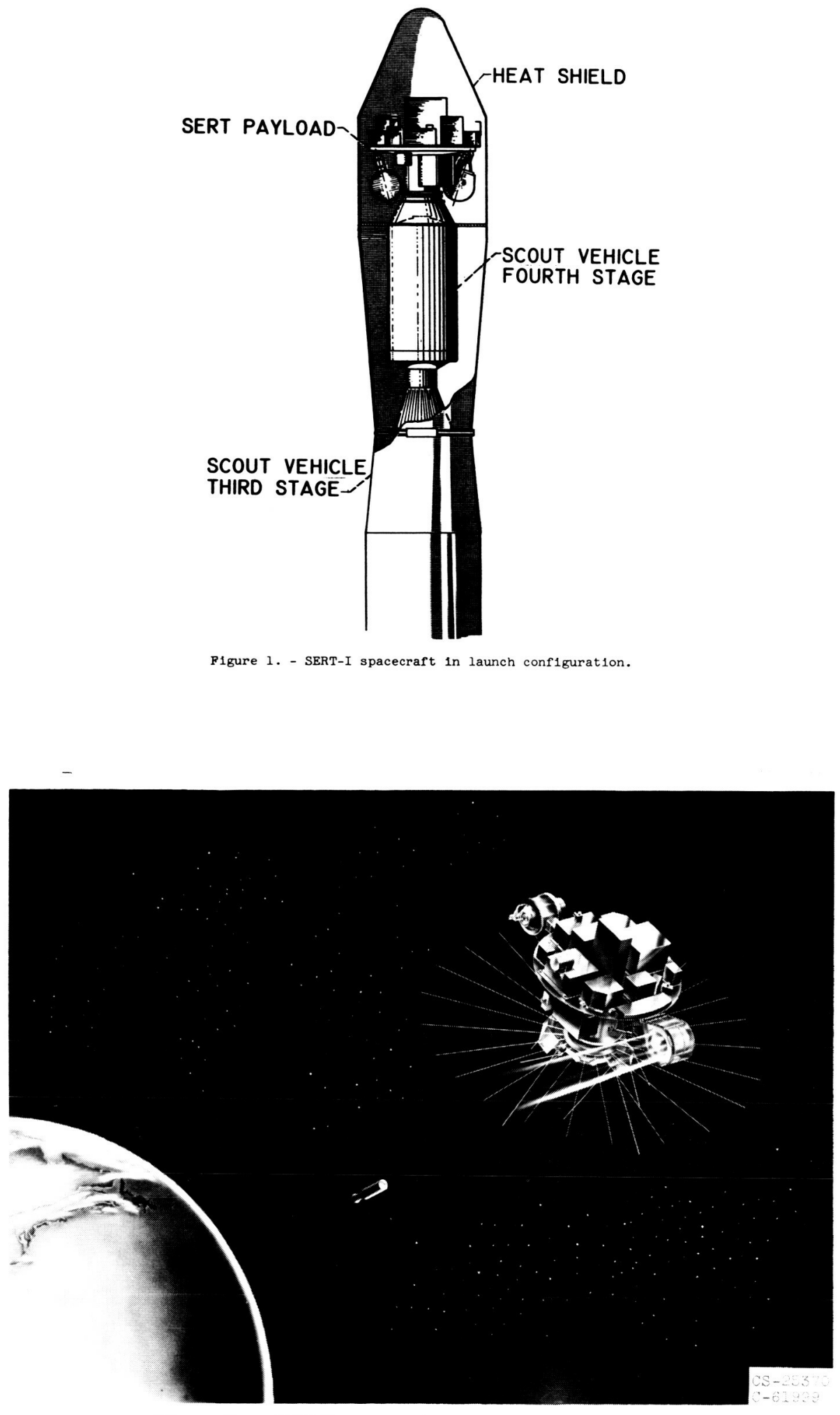

F1gure 2. - SERT-I spacecraft in flight conflguration. 


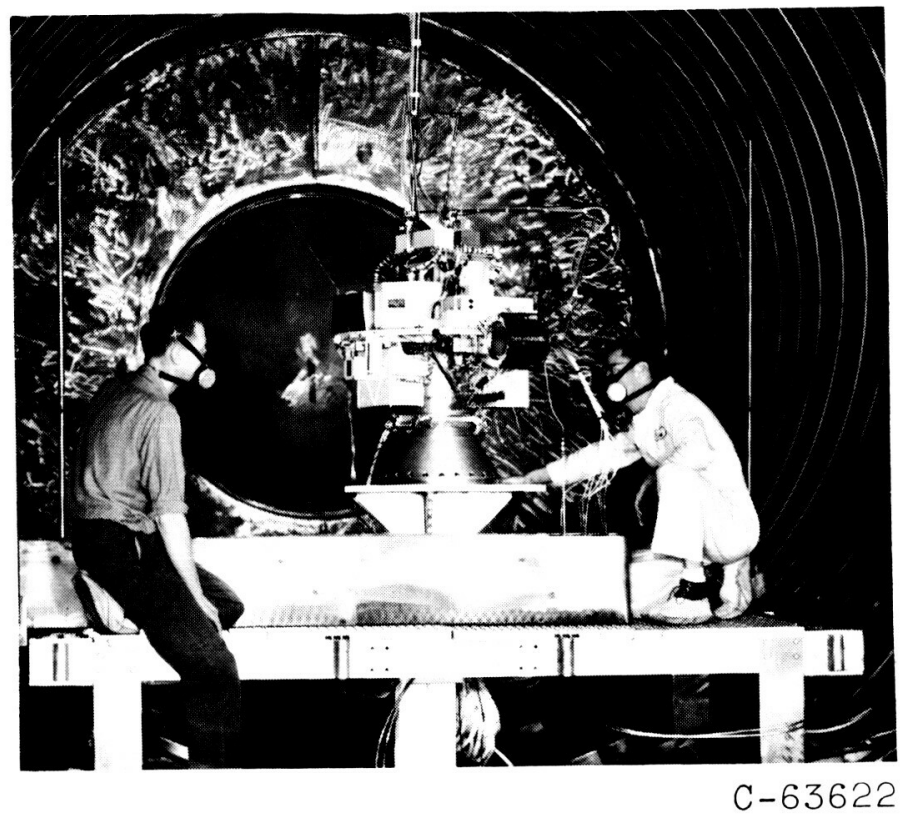

Figure 3. - Prototype SERT spacecraft in Lewis Research Center vacuum chamber.

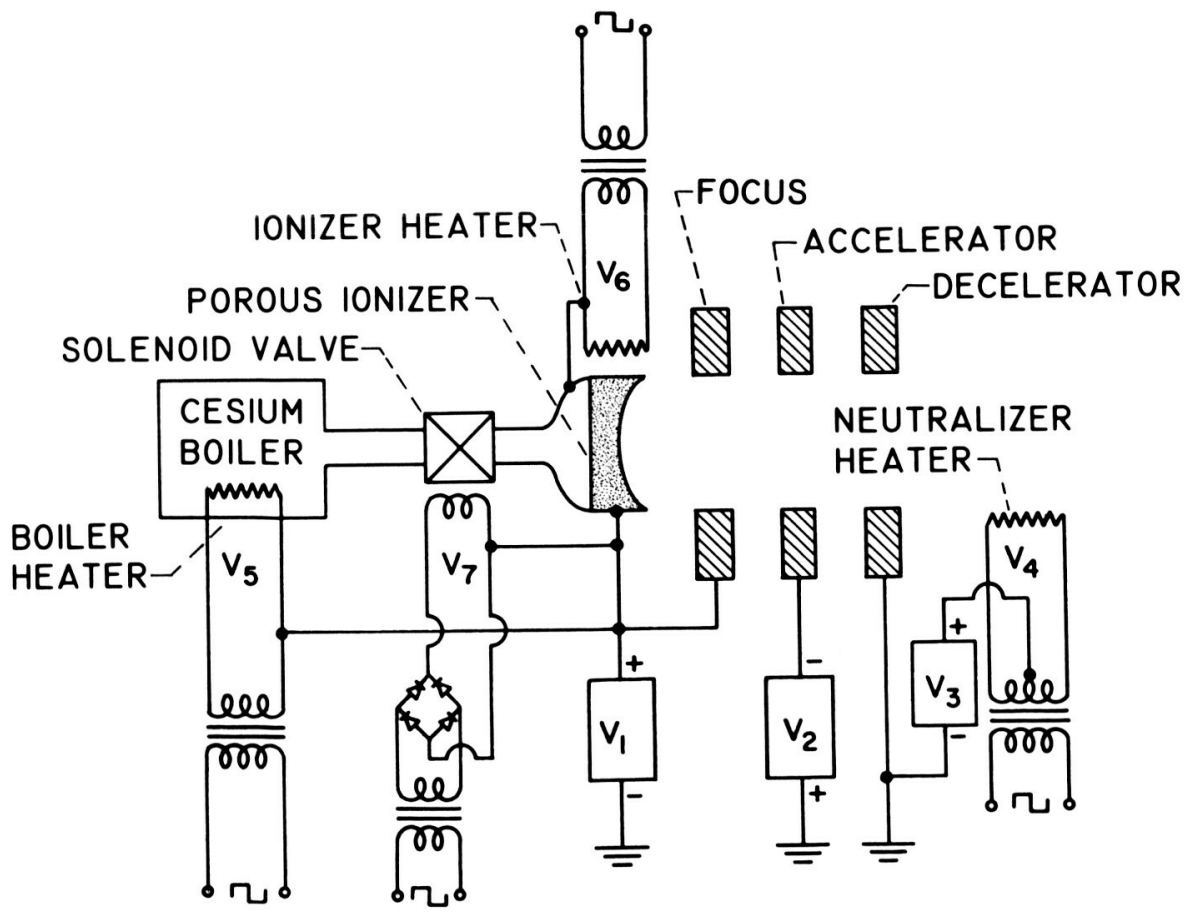

Figure 4. - Schematic diagram of contact-ionization thrustor. 


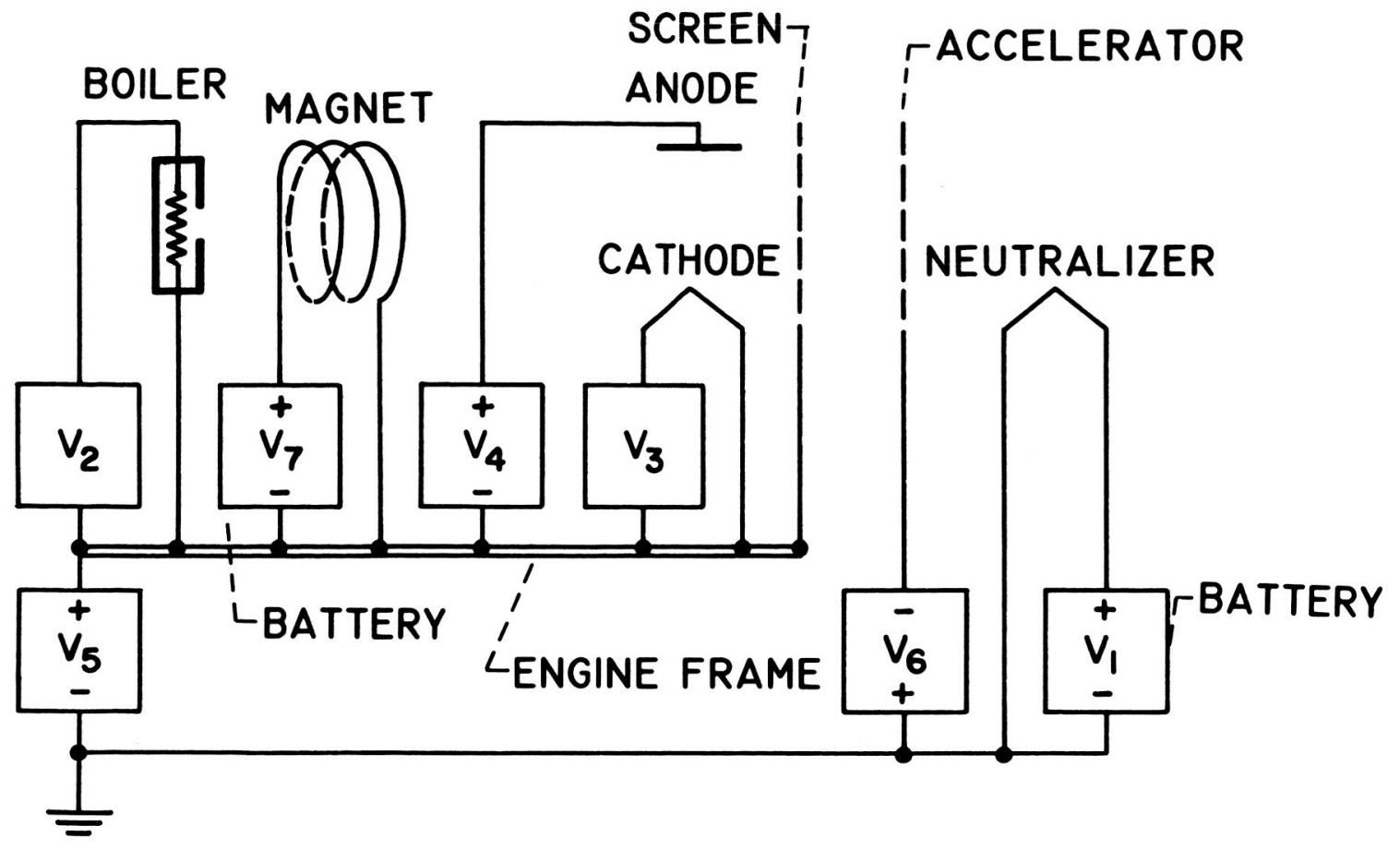

Figure 7. - Schematic diagram of electron-bombardment thrustor.

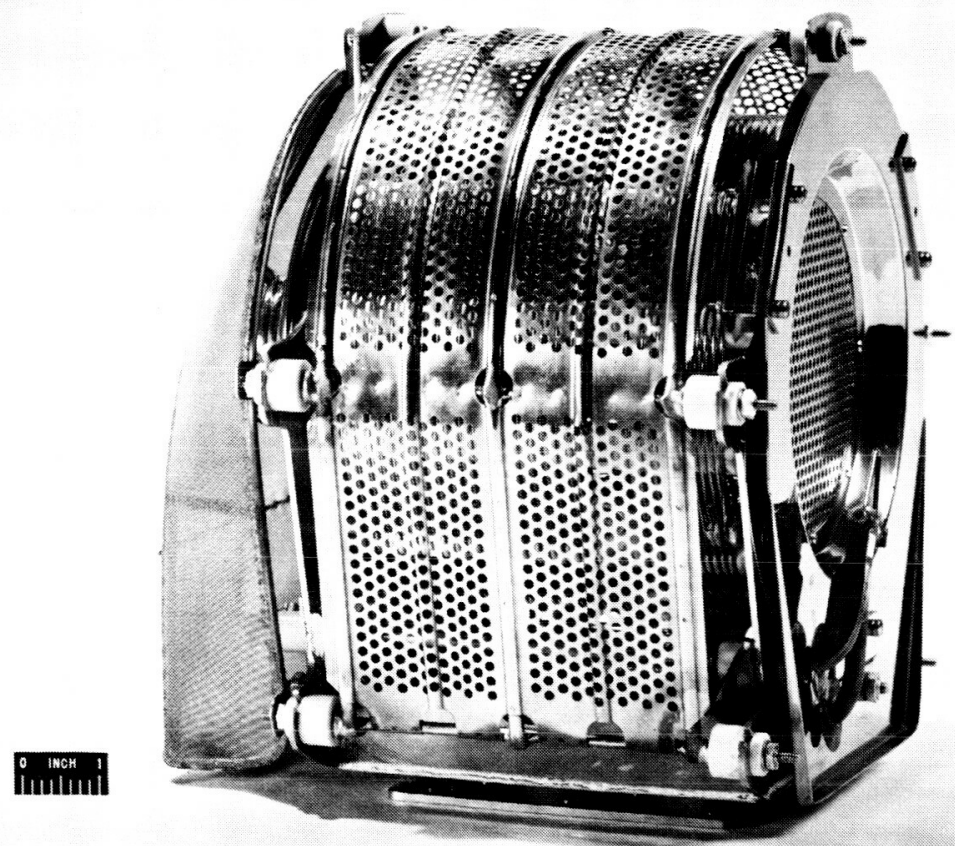

Figure 8. - Flight model electron-bombardment thrustor. 


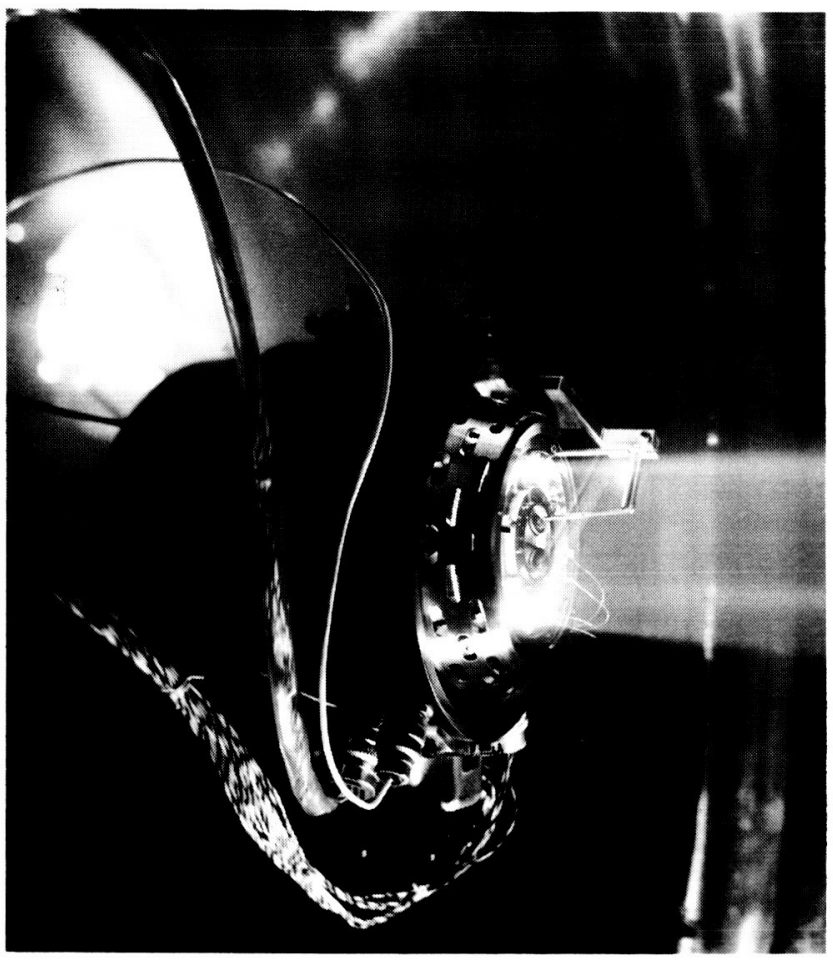

Figure 5. - View of contact-ionization thrustor during vacuum chamber operation.

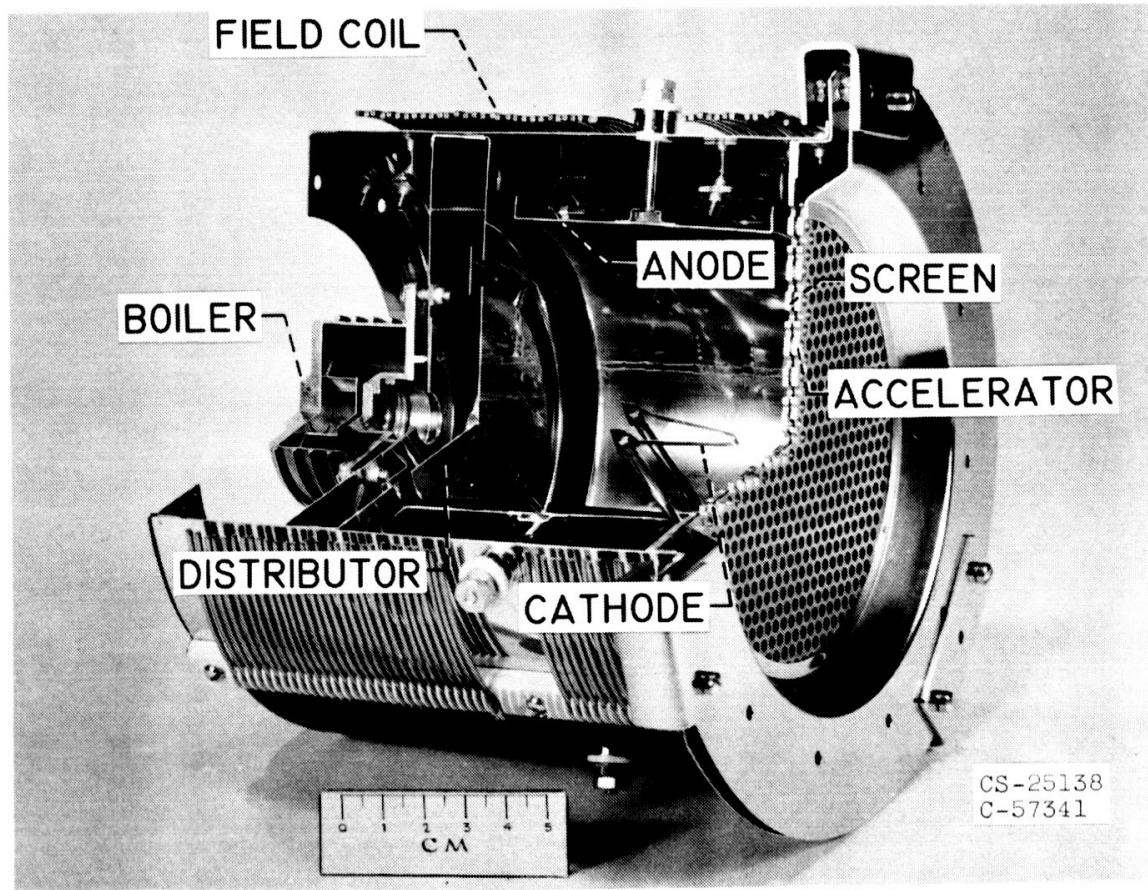

Figure 6. - Cutaway laboratory model of electron-bombardment thrustor. 